\title{
Determination of Spironolactone and Canrenone in Human Plasma by High-performance Liquid Chromatography with Mass Spectrometry Detection ${ }^{\dagger}$
}

\author{
Laurian Vlase, ${ }^{a}$ Silvia Imre, ${ }^{b, *}$ Dana Muntean, ${ }^{a}$ Marcela Achim, ${ }^{a}$ and Daniela-Lucia Muntean ${ }^{b}$ \\ ${ }^{a}$ Department of Pharmaceutical Technology and Biopharmaceutics, Faculty of Pharmacy, University of Medicine and \\ Pharmacy "Iuliu Haţieganu”, Victor Babeş street 8, RO-400012, Cluj-Napoca, Romania \\ ${ }^{\mathrm{b}}$ Department of Drug Analysis, Faculty of Pharmacy, University of Medicine and Pharmacy, Gheorghe Marinescu street \\ 38, RO-540139, Târgu-Mureş, Romania
}

RECEIVED SEPTEMBER 30, 2010; REVISED DECEMBER 21, 2010; ACCEPTED JANUARY 17, 2011

\begin{abstract}
A new simple, sensitive and LC-MS/MS method for quantification of spironolactone and its metabolite, canrenone, in human plasma is proposed. The analytes were analysed on a $\mathrm{C} 18$ column at $48{ }^{\circ} \mathrm{C}$, by using a mobile phase of $58 \%$ methanol, $42 \% 10 \mathrm{mmol} \mathrm{dm}^{-3}$ ammonim acetate in water and a flow rate of $1 \mathrm{~mL} / \mathrm{min}$. The detection of both analytes in plasma was performed as follows: ESI+, EIC $(\mathrm{m} / \mathrm{z}$ $169 ; 187 ; 283 ; 305$ ) from $\mathrm{m} / \mathrm{z} 341$, after protein precipitation with methanol. Calibration curves were generated over the ranges $2.77-184.50 \mathrm{ng} / \mathrm{mL}$ for spironolactone and $2.69-179.20 \mathrm{ng} / \mathrm{mL}$ for canrenone by using a weighted $(1 / y)$ linear regression. The absolute values of within- and between-run precision and accuracy for both analytes ranged between 3.1 and $13.9 \%$, and the mean recovery was $99.7 \%$. The analytes demonstrated good stability in various conditions. The validated method has been applied to a bioequivalence study of $50 \mathrm{mg}$ spironolactone tablets on healthy volunteers. (doi: 10.5562/cca1761)
\end{abstract}

Keywords: spironolactone, canrenone, LC-MS/MS, pharmacokinetics, plasma

\section{INTRODUCTION}

Spironolactone (SPR) is a mineralocorticoid (aldosterone) receptor antagonist (aldosterone antagonist) and a potassium-sparing diuretic. ${ }^{1}$ It is mainly metabolised in humans to $7 \alpha$-thiomethylspirolactone and canrenone (CNR) (Figure 1). SPR is indicated for the treatment of congestive heart failure, oedema and ascites in cirrhosis and primary hyperaldosteronism. Due to its antiandro-

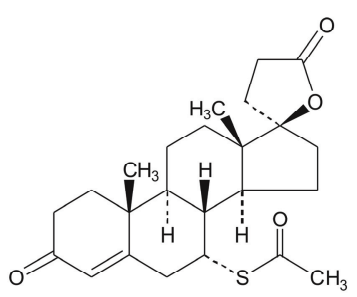

(a)

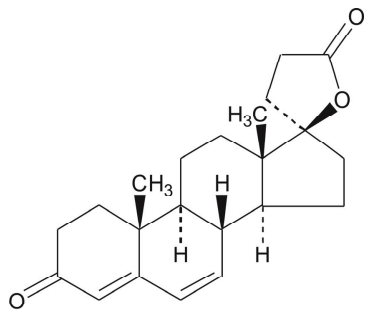

(b)
Figure 1. Chemical structures of spironolactone (a) and canrenone (b). gen effect, it can also be used to treat hirsutism, and is a common component in hormone therapy for male-tofemale transsexual and transgender people. It is also used for treating hair loss and acne in women, and can be used as a topical medication for treatment of male baldness.

Numerous HPLC methods have been developed for SPR and its metabolites determination in plasma or serum, ${ }^{2}$ and only a few used liquid chromatography coupled with mass spectrometry as analytical tool for this kind of determination. ${ }^{3,4}$ However, an important number of papers in which LC-MS determination of SPR from urine (doping agents screening) and milk are described. ${ }^{5-12}$

In the present study, we attempted to develop a fast and sensitive LC-MS/MS method able to quantify SPR and CNR in human plasma after oral administration of a single dose of $100 \mathrm{mg}(2 \times 50 \mathrm{mg})$ SPR by applying a simple protein precipitation, with a very short run-time. Finally, the developed and verified method was used for bioequivalence investigation of two oral medicinal products containing $50 \mathrm{mg}$ SPR.

\footnotetext{
$\dagger$ Presented at the $10^{\text {th }}$ International Symposium and Summer School on Bioanalysis within the CEEPUS Network CII-HU-001004-0910, Zagreb, Croatia, July 2010.

* Author to whom correspondence should be addressed. (E-mail: silsta@yahoo.com)
} 


\section{EXPERIMENTAL}

\section{Reagents}

Spironolactone and canrenone were European Pharmacopoeia certified reference standards. Methanol and ammonium acetate were Merck products (Merck KgaA, Darmstadt, Germany). Ultrapure, deionised water was produced by a Millipore (Millipore SA, Molsheim, France) water system. The human blank plasma was supplied from healthy volunteers.

\section{Standard Solutions}

Two stock solutions of SPR and CNR with concentration of $1.3 \mathrm{mg} / \mathrm{mL}$ and $0.45 \mathrm{mg} / \mathrm{mL}$, respectively, were prepared by dissolving appropriate quantities of reference substances (weighed on an analytical balance Analytical Plus from Ohaus, USA) in $10 \mathrm{~mL}$ methanol. Two working solutions were then obtained by diluting specific volumes of each stock solution with methanol. Eight plasma calibration standard with the following concentration domains were obtained for each analyte: 2.8 $184.5 \mathrm{ng} / \mathrm{mL}$ SPR and 2.7-179.2 ng/mL CNR. Accuracy and precision of the method were verified using quality control (QC) plasma standards with three levels of concentration: QCA - 9.23 ng/mL SPR, $8.96 \mathrm{ng} / \mathrm{mL}$ CNR; QCB - $27.68 \mathrm{ng} / \mathrm{mL}$ SPR and $26.88 \mathrm{ng} / \mathrm{mL}$ CNR; QCC -73.81 ng/mL SPR and $71.68 \mathrm{ng} / \mathrm{mL}$ CNR. The same types of quality control samples (QC) were used during clinical samples analysis in order to further evaluate the accuracy of the method.

\section{Chromatographic and Mass Spectrometry Systems and Conditions}

The HPLC system was an 1100 series model (Agilent Technologies, USA) consisting of a binary pump, an inline degasser, an autosampler, a column thermostat, and an Ion Trap SL mass spectrometer detector (Brucker Daltonics GmbH, Germany). Chromatograms were processed using QuantAnalysis software. The detection of the analytes: ESI+, EIC $(m / z 169,187 ; 283 ; 305)$ from $\mathrm{m} / \mathrm{z} 341$. Other detector parameters were: dry temperature $225^{\circ} \mathrm{C}$, nebulizer $60 \mathrm{psi}$, dry gas - nitrogen at $12 \mathrm{~L} / \mathrm{min}$, ion charge control $\mathrm{ON}$, accumulation time $400 \mathrm{~ms}$. The electrospray capillary was set to $4000 \mathrm{~V}$ for spironolactone and $2000 \mathrm{~V}$ for canrenone. The chromatographic separation was performed at $48{ }^{\circ} \mathrm{C}$ on a Zorbax SB-C18 $100 \times 3.0 \mathrm{~mm}, 3.5 \mu \mathrm{m}$ (Agilent Technologies), protected by an in-line filter.

\section{Mobile Phase}

The mobile phase consisted of a mixture of $58 \%$ methanol and $42 \% 10 \mathrm{mmol} \mathrm{dm}^{-3}$ ammonim acetate in water, each component being degassed, before elution, for 10 minutes in a $\mathrm{T} 700 \mathrm{H}$ (Elma Transsonic, Singen, Germany) ultrasonic bath. The pump delivered the mobile phase at $1 \mathrm{~mL} / \mathrm{min}$.

\section{Sample Preparation}

Standard and test plasma samples were prepared as follows in order to be chromatographically analyzed. In an Eppendorf tube, to $0.2 \mathrm{ml}$ plasma, a volume of $0.5 \mathrm{ml}$ methanol was added. The tube was vortexmixed for 10 seconds via Genie 2 vortex (Scientific Industries, USA) and then centrifuged for 6 minutes at 4000 rpm (204 Sigma centrifuge, Osterode am Harz, Germany). The supernatant was transferred in an autosampler vial and $10 \mu \mathrm{L}$ were injected into the chromatographic system.

\section{Analytical Performances of the Method}

Specificity of the method was investigated by analysing blank plasma samples of six individual healthy volunteers for interference of endogenous compounds with the analytes. Investigation of the selectivity was carried out together with the calibration curve assay. In order to prove selectivity, chromatograms of the blank plasma extracts must not exhibit significant peak at the retention time of the examined peaks. The result was considered acceptable if the peak height of the endogenous compound at the retention time of analyte was not more than $20 \%$ of the mean peak height obtained for the lowest level calibration solution.

The matrix effect was also investigated. The ion suppression was calculated as relative difference between the analytical response for a mixture of SPR and $\mathrm{CNR}$ at quantification limit injected directly in mobile phase and the response of analytes added to preextracted blank plasma samples. ${ }^{13}$

The concentration of analytes in plasma samples was determined automatically by the instrument data system using the external standard method. Linearity verification was performed using singlicate calibration standards on five different days. The calibration curve model was determined by the least squares analysis. The applied calibration model was a linear one: $y=a x+b$, weight $1 / y$, where $y$ - peak area and $x$ - concentration, in $\mathrm{ng} / \mathrm{mL}$. Distribution of the residuals (\% difference of the back-calculated concentration from the nominal concentration) was investigated. The calibration model was accepted, if the residuals were within $\pm 20 \%$ at the lower limit of quantification (LLOQ) and within $\pm 15 \%$ at all other calibration levels and at least six out of eight calibration standards met this criterion, including highest and lowest calibration levels.

The LLOQ was investigated at the level of the lowest calibration standard, when the accuracy and precision have to be less than $20 \%$. 
The within- and between-run precision (expressed as coefficient of variation, $\mathrm{CV} \%$ ) and accuracy (expressed as relative difference between obtained and theoretical concentration, Bias\%) of the assay procedure were determined by analysis on the same day of five different samples at each of the lower (QCA), medium (QCB), and higher (QCC) levels of the considered concentration range and one different sample of each on five different days, respectively.

The relative recoveries at each of the previously three levels of concentration and LLOQ were measured by comparing the response of the treated plasma standards with the response of standards in solution with the same concentration of analytes as the prepared plasma sample.

The stability of the analytes in human plasma was investigated in four ways, in order to characterize each operation during the process of bioequivalence studies: room temperature stability (RTS), post-preparative stability (PPS) in autosampler, freeze-thaw stability (FTS) and long-term stability (LTS) below $-25{ }^{\circ} \mathrm{C}$. For all stability studies, plasma standards at each of the lower (QCA) and higher (QCC) QC levels were used. Four pairs were prepared and let at room temperature for four hours, then processed and analyzed. Eight pairs were prepared and processed, four pairs were immediately analyzed and the other four stored in the HPLC autosampler $\left(20^{\circ} \mathrm{C}\right)$ (PPS study). The stored samples were injected after 3.5 hours, the expected longest storage times of the samples in autosampler before injection. For the freeze-thaw stability (FTS), four aliquots at the same low and high concentrations were prepared. These samples were subjected to three cycles of freezethaw operations in three consecutive days. After the third cycle the samples were analyzed against calibration curve of the day. The mean concentration calculated for the samples subjected to the cycles and the nominal ones were compared. For long-term stability (LTS), in the first validation day, four pairs were prepared and analyzed and concentration values were determined against calibration curve of the day. Other four sets were stored in freezer below $-25{ }^{\circ} \mathrm{C}$ and analyzed together with calibration samples on four different occasions during three months. The values were calculated against calibration curve of the day and the mean values for the stored samples and nominal concentrations were compared. The requirement for stable analytes was that the difference between mean concentrations of the tested samples in various conditions and nominal concentrations had to be in $\pm 15 \%$ range.

The ability to dilute samples with concentrations above the upper limit of quantification was also investigated. Plasma standards $(n=5)$ with $922.6 \mathrm{ng} / \mathrm{mL} \mathrm{SPR}$ and $896 \mathrm{ng} / \mathrm{mL} \mathrm{CNR}$ were ten times diluted with plasma then processed and analyzed. The mean concentration found was compared with the nominal value. The accuracy and precision had to be within $\pm 15 \%$ range.

\section{Clinical Application}

The validated method was applied in a bioequivalence study of two dosage forms - tablets containing $50 \mathrm{mg}$ SPR, after oral administration of $100 \mathrm{mg}$ SPR. Seventeen collecting times within 72 hours were used. The accuracy of the validated method was monitored to ensure that it continued to perform satisfactorily during analysis of volunteer samples. To achieve this objective, a number of QC samples prepared in duplicate at three concentration levels were analyzed in each assay run and the results compared with the corresponding calibration curve. The runs were accepted if at least four out of six QC were within $\pm 15 \%$.

\section{RESULTS AND DISCUSSION}

The recorded mass spectrum of canrenone is presented in Figure 2.

During electrospray evaporation and ionization process, spironolactone readily loses the $7 \alpha$-acetylthio group being transformed to canrenone, so it was quantified in that form. However, the spironolactone signal can be easy distinguished from the canrenone signal by different retention times of the two compounds.

A blank, a plasma standard sample at quantification limit and a clinical sample are shown in Figure 3. No significant interferences at the retention time of SPR (2.9 $\mathrm{min}$ ) and CNR (3.8 $\mathrm{min}$ ) were observed in different plasma blank samples chromatograms due to the specificity of selected signals.

However, during the method development and using a capillary potential of $4000 \mathrm{~V}$, an interfering peak with retention time of 3.5 min was observed near canrenone, making its quantification difficult (Figure 4). The mass spectrum of the interfering peak was found to

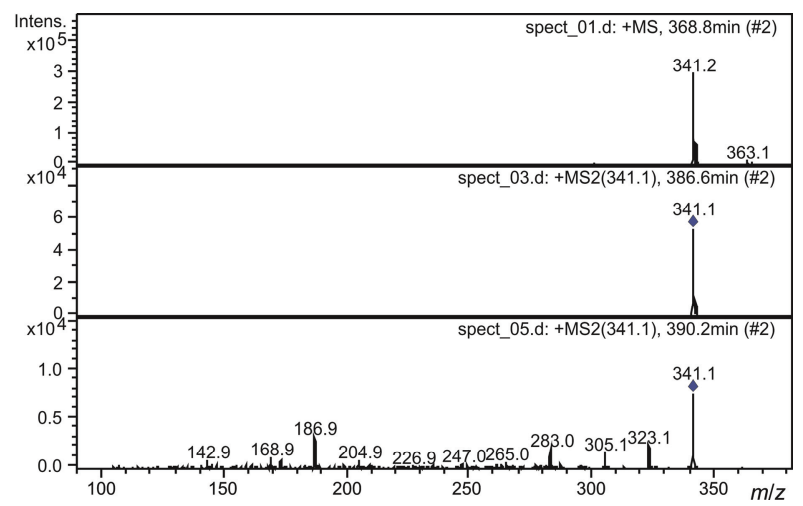

Figure 2. MS spectra of canrenone: upper: full scan spectra in mobile phase, middle: isolation of $\mathrm{m} / \mathrm{z} 341$, lower: fragmentation spectra (MS/MS). 


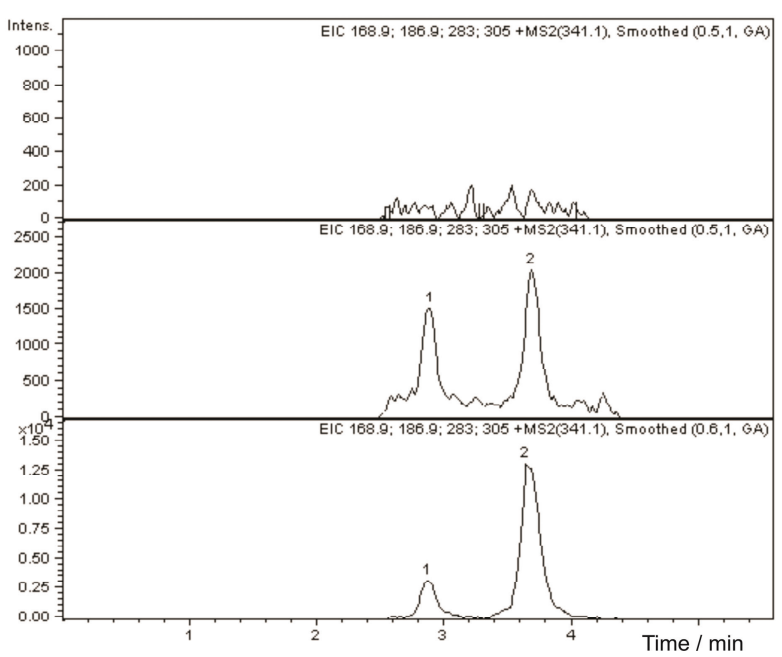

Figure 3. Chromatograms of blank plasma (upper image), plasma spiked with SPR (1) and CNR (2) at LLOQ (middle) and a clinical sample obtained at 2 hours after oral administration of $100 \mathrm{mg}$ SPR to a healthy volunteer; found concentrations: SPR $-16.6 \mathrm{ng} / \mathrm{ml}, \mathrm{CNR}-63.3 \mathrm{ng} / \mathrm{ml}$ (lower image).

be identical to that of canrenone, so it may be another metabolite of spironolactone which, as spironolactone, is easily transformed in canrenone during ionization and solvent evaporation (cross-talking). However, by lowering the capillary voltage from $4000 \mathrm{~V}$ to $2000 \mathrm{~V}$, that interference became negligible, probably due to milder ionization conditions in electrospray ion source at lower voltages which minimize the cross-talking process. This kind of interference due to sample structurally-related compounds was already reported in literature. $^{14}$

No significant matrix effects - ion suppression were observed for SPR or CNR when comparing the analytical signal obtained for analytes dissolved in mobile phase or in blank plasma sample extracts. The analyte carryover was verified using a blank injection made right after an injection of the most elevated level of concentration from

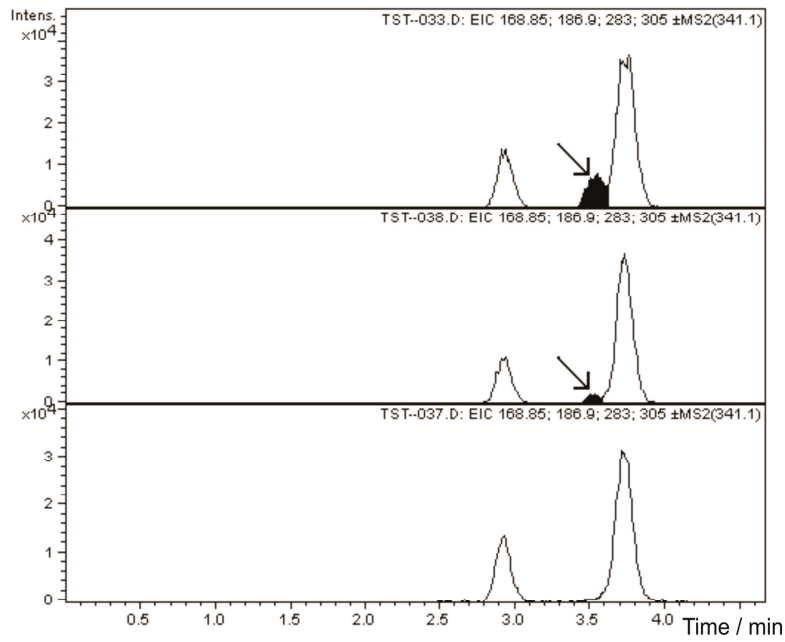

Figure 4. Effect of electrospray capillary voltage on method selectivity for canrenone (RT $3.7 \mathrm{~min}$ ): upper image: $4000 \mathrm{~V}$, middle: $3000 \mathrm{~V}$, lower: $2000 \mathrm{~V}$. The interfering peak with RT 3.5 min is marked with an arrow.

calibration curve. No interference was observed at the retention times of the analytes as a result of carryover.

The applied calibration curve model proved to correlate adequately with the experimental data over the concentration range $2.77-184.50 \mathrm{ng} / \mathrm{mL}$ for SPR and 2.69$179.20 \mathrm{ng} / \mathrm{mL}$ for CNR (correlation coefficient greater than 0.993$)$. The mean calibration curves $(N=8$ calibration points, $n=5$ determinations for each calibration point) were: for SPR $y=2922( \pm 352) x-1121( \pm 779)$, for CNR $y=3883( \pm 229) x-1947( \pm 505)$. The residuals of the calibration points had no tendency of variation with concentration and at least six out of eight were within \pm 15 $\%$, including LLOQ and upper limit of quantification.

The method had within- and between-run accuracy and precision (Tables 1 and 2), in agreement to international regulations regarding bioanalytical methods validation. ${ }^{15,16}$ The lower limits of quantification were established at $2.77 \mathrm{ng} / \mathrm{mL}$ for SPR and $2.69 \mathrm{ng} / \mathrm{mL}$ for

Table 1. Within-run precision, accuracy and recovery for SPR and CNR $(n=5)$

\begin{tabular}{|c|c|c|c|c|c|c|c|}
\hline \multicolumn{2}{|c|}{$c_{\text {nominal }} / \mathrm{ng} \mathrm{ml}^{-1}$} & \multicolumn{2}{|c|}{$\begin{array}{c}\text { Mean } c_{\text {found }} / \mathrm{ng} \mathrm{ml}^{-1}( \pm \mathrm{SD}) \\
\text { Recovery } / \%( \pm \mathrm{SD})\end{array}$} & \multicolumn{2}{|c|}{$\mathrm{CV} / \%$} & \multicolumn{2}{|c|}{ Bias / \% } \\
\hline SPR & CNR & SPR & CNR & SPR & CNR & SPR & CNR \\
\hline 2.77 & 2.69 & $\begin{array}{c}2.94(0.20) \\
100.60(8.20)\end{array}$ & $\begin{array}{c}2.86(0.15) \\
97.30(6.21)\end{array}$ & 6.7 & 5.1 & 6.1 & 6.3 \\
\hline 9.23 & 8.96 & $\begin{array}{c}9.77(0.51) \\
97.41(5.40)\end{array}$ & $\begin{array}{c}8.65(0.27) \\
92.93(3.08)\end{array}$ & 5.2 & 3.1 & 5.9 & -3.4 \\
\hline 27.68 & 26.88 & $\begin{array}{c}28.76(2.65) \\
111.00(10.38)\end{array}$ & $\begin{array}{c}27.95(1.45) \\
105.72(5.64)\end{array}$ & 9.2 & 5.2 & 3.9 & 4.0 \\
\hline 73.81 & 71.68 & $\begin{array}{c}71.26(7.58) \\
110.57(11.80)\end{array}$ & $\begin{array}{l}66.61(2.50) \\
98.12(3.72)\end{array}$ & 10.6 & 3.7 & -3.5 & -7.1 \\
\hline
\end{tabular}


Table 2. Between-run precision, accuracy and recovery for SPR and CNR $(n=5)$

\begin{tabular}{|c|c|c|c|c|c|c|c|}
\hline \multicolumn{2}{|c|}{$c_{\text {nominal }} / \mathrm{ng} \mathrm{ml}^{-1}$} & \multicolumn{2}{|c|}{$\begin{array}{c}\text { Mean } c_{\text {found }} / \mathrm{ng} \mathrm{ml}^{-1}( \pm \mathrm{SD}) \\
\text { Recovery } / \%( \pm \mathrm{SD})\end{array}$} & \multicolumn{2}{|c|}{$\mathrm{CV} / \%$} & \multicolumn{2}{|c|}{ Bias / \% } \\
\hline SPR & $\mathrm{CNR}$ & SPR & $\mathrm{CNR}$ & SPR & CNR & SPR & CNR \\
\hline 2.77 & 2.69 & $\begin{array}{c}2.89(0.36) \\
102.41(10.80)\end{array}$ & $\begin{array}{c}2.69(0.26) \\
99.14(8.97)\end{array}$ & 12.4 & 9.7 & 4.3 & -0.1 \\
\hline 9.23 & 8.96 & $\begin{array}{c}9.12(0.56) \\
112.03(14.31)\end{array}$ & $\begin{array}{c}8.41(0.47) \\
105.71(11.52)\end{array}$ & 6.1 & 5.6 & -1.2 & -6.1 \\
\hline 27.68 & 26.88 & $\begin{array}{c}24.96(3.48) \\
94.06(12.96)\end{array}$ & $\begin{array}{c}26.68(2.03) \\
101.54(5.61)\end{array}$ & 13.9 & 7.6 & -9.8 & -0.7 \\
\hline 73.81 & 71.68 & $\begin{array}{c}67.50(7.81) \\
108.14(15.88)\end{array}$ & $\begin{array}{l}64.62(6.11) \\
98.03(6.21)\end{array}$ & 11.5 & 9.5 & -8.5 & -9.9 \\
\hline
\end{tabular}

Table 3. Results of the stability studies $(n=4)$

\begin{tabular}{|c|c|c|c|c|c|c|c|c|}
\hline & \multicolumn{2}{|c|}{ RTS } & \multicolumn{2}{|c|}{ PPS } & \multicolumn{2}{|c|}{ FTS } & \multicolumn{2}{|c|}{ LTS } \\
\hline $\begin{array}{c}c_{\text {nominal }} / \mathrm{ng} \mathrm{ml}^{-1} \\
\mathrm{SPR} / \mathrm{CNR}\end{array}$ & $9.23 / 8.96$ & $73.81 / 71.68$ & $9.23 / 8.96$ & $73.81 / 71.68$ & $9.23 / 8.96$ & $73.81 / 71.68$ & $9.23 / 8.96$ & $73.81 / 71.68$ \\
\hline Bias / \%, SPR & -8.9 & -10.2 & -4.3 & -13.2 & -8.8 & -11.3 & -10.7 & -9.3 \\
\hline Bias / $\%$, CNR & -9.8 & -5.9 & -11 & -10.5 & -11.6 & -7.8 & -3.2 & -7.9 \\
\hline
\end{tabular}

*RTS - room temperature stability (four hours), PPS - post-preparative stability $\left(20^{\circ} \mathrm{C}, 3.5\right.$ hours), $\mathrm{FTS}$ - freeze - thaw stability ( 3 freeze-thaw cycles), LTS - long term stability $\left(-28^{\circ} \mathrm{C}\right.$, three months).

CNR, respectively, with accuracy and precision less than $20 \%$ (Tables 1 and 2).

The recovery was consistent and reproducible (Tables 1 and 2).

The analytes proved their stability under various conditions (Table 3), the Bias\% of found concentration being less than $15 \%$, the maximum accepted value for method's accuracy.

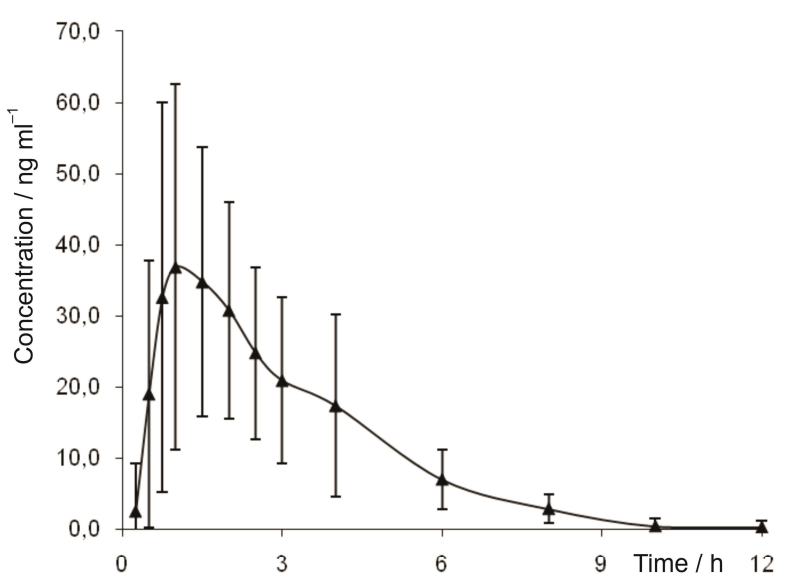

Figure 5. Mean concentration profiles of SPR $(\boldsymbol{\Delta})$ and $\mathrm{CNR}$ ( $n=24$ volunteers).
The sample dilution could be made with accuracy within $\pm 9.5 \%$ range and precision less than $11.2 \%$, for both analytes within- and between-assay.

The validated method was verified during analysis of clinical samples from a bioequivalence study (24 healthy volunteers) of two medicines containing $50 \mathrm{mg}$ SPR. Figure 5 shows the mean concentration profiles of SPR and CNR, after oral administration of $100 \mathrm{mg}$ SPR.

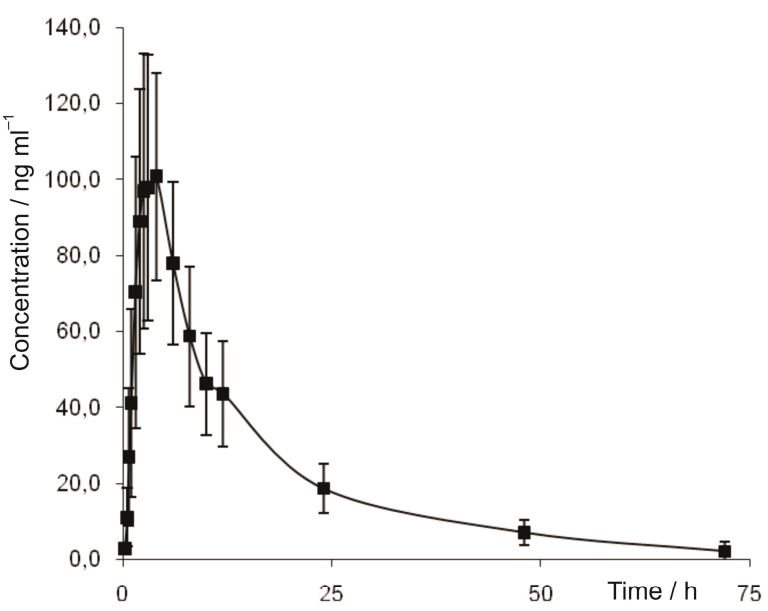

in plasma after oral administration of $100 \mathrm{mg}$ spironolactone Croat. Chem. Acta 84 (2011) 361. 
The method continued to perform in terms of accuracy during the analysis of clinical samples, in each analytical run not more than two out of six QC samples being outside of $\pm 15 \%$ nominal value, but not all two at the same concentration.

There are only few articles about SPR and CNR determination in human plasma by LC-MS/MS. The proposed method has real advantages in terms of sensitivity and high-throughput features. The necessary plasma volume allows the analysis of paediatric plasma samples, too. The analytes could be determined with accuracy and precision for quantities starting from $7.8 \mathrm{pg}$ injected into column, in comparison with another method in which a run time of 13 minutes and time and material consuming sample preparation like liquid-liquid extraction were applied in order to determin quantities above $200 \mathrm{pg}$ injected. ${ }^{3}$ Another advantage of the actual method is the high sample throughput due to the sample preparation by protein precipitation combined with a short run-time of analysis, in comparison with a recent article in which protein precipitation is used, but large injection volume (corresponding to $133 \mathrm{pg}$ of analytes injected) and long runtime (14 minutes) were necessary to achieve the objectives. $^{17}$

\section{CONCLUSION}

The proposed method provides accuracy and precision for quantitative determination of spironolactone and canrenone in human plasma after oral administration of $100 \mathrm{mg}$ spironolactone. The simple sample preparation by protein precipitation, the relatively short run time and the selected signals for monitoring allowed a specific and efficient analysis of plasma samples, making the method more productive and thus more cost effective. As far as we are aware, this is the first high throughput LC-MS/MS method for spironolactone and canrenone quantification in human plasma after protein precipita- tion by using the same monitoring ions for both analytes.

\section{REFERENCES}

1. L. Brunton, K. Parker, D. Blumenthal, I. Buxton, Goodman and Gilman's Manual of Pharmacology and Therapeutics, McGrawHill, 2008, pp. 494-497.

2. J. M. Sandall, J. S. Millership, P. S. Collier, and J. C. McElnay, J. Chromatogr. B 839 (2006) 36-44.

3. H. Dong, F. Xu, Z. Zhang, Y. Tian, and Y. Chen, J. Mass Spectrom. 41 (2006) 477-486.

4. F. G. Xu, Z. J. Zhang, H. J. Dong, Y. Tian, Y. Liu, and Y. Chen, Arzneimittelforschung $\mathbf{5 8}$ (2008) 117-121.

5. K. Deventer, F. T. Delbeke, K. Roels, and P. Van Eenoo, Biomed. Chromatogr. 16 (2002) 529-535.

6. K. Deventer, O. J. Pozo, P. Van Eenoo, and F. T. Delbeke, J. Chromatogr. A 1216 (2009) 5819-5827.

7. V. Sanz-Nebot, I. Toro, R. Bergés, R. Ventura, J. Segura, and J. Barbosa, J. Mass Spectrom. 36 (2001) 652-657.

8. M. Kolmonen, A. Leinonen, A. Pelander, and I. Ojanperä, Anal. Chim. Acta 585 (2007) 94-102.

9. F. Badoud, E. Grata, L. Perrenoud, L. Avois, M. Saugy, S. Rudaz, and J.-L. Veuthey, J. Chromatogr. A 1216 (2009) 4423-4433.

10. F. Badoud, E. Grata, L. Perrenoud, M. Saugy, S. Rudaz, and J.L. Veuthey, J. Chromatogr. A 1217 (2010) 4109-4119.

11. M. A. Dikunets, S. A. Appolonova, and G. M. Rodchenkov, J. Anal. Chem. 64 (2009) 832-842.

12. B. Shao, J. Zhang, Y. Yang, J. Meng, Y. Wu, and H. Duan, Rapid Commun. Mass Spectrom. 22 (2008) 3427-3433.

13. T. M. Annesley, Clin. Chem. 49 (2003) 1041-1044.

14. L. Vlase, B. Kiss, S.E. Leucuta, and S. Gocan, J. Liq. Chrom. Relat. Techn. 32 (2009) 2105-2121.

15. U. S. Department of Health and Human Services, Food and Drug Administration, Center for Drug Evaluation and Research. Guidance for Industry. Bioavailability and Bioequivalence studies for orally administered drug products - general considerations, March 2003, Rockville, USA, http://www.fda.gov/cder/guidance/5356fnl.pdf

16. U.S. Department of Health and Human Services, Food and Drug Administration, Guidance for Industry - Bioanalytical Method Validation, May 2001, http:/www.fda.gov/cder/guidance/4252fnl.pdf

17. D. I. Sora, S. Udrescu, F. Albu, V. David, and A. Medvedovici, J. Pharm. Biomed. Anal. 52 (2010) 734-740. 